\title{
AMMERER, Gerhard, WEIß, Alfred Stefan, Strafe, Disziplin und Besserung. Österreichische Zucht- und Arbeitshäuser von 1750 bis 1850
}

\section{(2) OpenEdition \\ Journals}

Édition électronique

URL : http://journals.openedition.org/ifha/494

DOI : $10.4000 /$ ifha.494

ISSN : 2198-8943

Éditeur

IFRA - Institut franco-allemand (sciences historiques et sociales)

Référence électronique

"AMMERER, Gerhard, WEIß, Alfred Stefan, Strafe, Disziplin und Besserung. Österreichische Zucht- und Arbeitshäuser von 1750 bis 1850 », Revue de I'IFHA [En ligne], Date de recension, mis en ligne le 01 janvier 2009, consulté le 22 septembre 2020. URL : http://journals.openedition.org/ifha/494; DOI : https://doi.org/10.4000/ifha.494

Ce document a été généré automatiquement le 22 septembre 2020.

(CIFHA 


\section{AMMERER, Gerhard, WEIß, Alfred Stefan, Strafe, Disziplin und Besserung. Österreichische Zucht- und Arbeitshäuser von 1750 bis 1850}

1 L'histoire des maisons de correction de l'époque moderne n'en est plus au stade de la découverte pour les historiens. Après une vague de travaux entrepris dans les années 1970 et 1980 en mettant l'accent sur l'histoire économique et le processus de disciplinarisation dans lequel s'inscrivit l'émergence de ces institutions, les Zuchthäuser n'ont pourtant plus beaucoup préoccupé les historiens allemands ou autrichiens. Ce n'est que ces dernières années qu'un intérêt renouvelé est apparu, avec des questionnements centrés davantage sur l'histoire du quotidien et sur les rapports du pouvoir à l'intérieur de ces institutions trop souvent appréhendées comme de simples vecteurs d'une répression traversant les sociétés d'autrefois du haut vers le bas. L'ouvrage dirigé par G.A. et A.S.W. se veut le reflet de cette nouvelle historiographie dans l'espace germanique en rouvrant à nouveau le dossier des institutions de l'enfermement en Autriche, qui avaient déjà fait, en 1978, l'objet d'une étude remarquée de l'historien viennois $\mathrm{H}$. Stekl.

2 L'ouvrage se divise en sept parties. Après une longue introduction écrite par G. AMMERER et dans laquelle sont retracées les grandes lignes de l'évolution des maisons de correction autrichiennes entre 1750 et 1850 sous l'influence des conjonctures politiques, sociales, mais aussi philosophiques et du droit pénal, six textes présentent les institutions se trouvant dans les différentes villes du pays : Vienne (M. SCHEUTZ), Innsbruck (G. AMMERER et A. S. WEIß), Graz (E. HAMMER-LUZA), Klagenfurt (A. S. WEIß), Salzbourg (H. BENEDER et A. S. WEIß) et Linz (A. S. WEIß). Ayant souvent recours aux sources de première main, ces études montrent une grande homogénéité quant à leur structure, mais aussi quant à leur contenu. Partout on rencontre les mêmes problèmes auxquels les contemporains étaient confrontés : multifonctionnalité des institutions, manque de ressources, échec de toute tentative pour rendre rentable l'existence des maisons par le travail des internés, porosité de l'espace et défaillances 
de la surveillance, encombrement, incapacité du personnel à répondre aux exigences d'un dispositif disciplinaire... À plusieurs reprises, les auteurs font également apparaître les réactions des internés (ennui, haine, désespoir, agressions dirigées contre leur propre corps).

3 On apprécie surtout dans les différents textes le souci de ne pas regarder la réalité des maisons de corrections sous un seul angle, mais de faire ressortir leurs multiples buts souvent contradictoires (amendement, disciplinarisation, punition, assistance aux personnes malades ou indigentes). À notre grand regret, la question du pourquoi de cette multiplicité de fonctions n'est qu'effleurée. Malgré un effort notable des auteurs pour rendre plus visible les personnes internées, les expériences et actions de celles-ci restent, faute de sources, en grande partie inaccessibles. Inconvénient de la structure de l'ouvrage, les textes sont, en outre, parfois quelque peu répétitifs. Remarquons cependant que quelques-uns d'entre eux approfondissent des aspects particuliers : la perception de l'enfermement par les «touristes » en visite (M. SCHEUTZ) ou bien le travail du personnel surveillant (A. S. WEIß). L'étude de l'architecture des maisons, présente dans quasiment toutes les contributions, nous apprend d'ailleurs qu l'un des traits caractéristiques de la prison contemporaine, à savoir l'enfermement cellulaire, a bel et bien déjà été pratiqué au XVIIIe s. (à Graz, en 1732, p. 132) - même si cette pratique, par un manque de moyens financiers, a dû être abandonnée quelques années plus tard. C'est par de tels détails que se dévoile la richesse des recherches dont ce livre est le fruit.

Falk BRETSCHNEIDER (Centre de Recherches Interdisciplinaires sur l'Allemagne, Paris) 